\title{
Investigating the impact of consumer values and advocacy behavior on buying decision satisfac- tion: A study through gender lens
}

\author{
Raja Ahmed Jamil ${ }^{a^{*}}$, Syed Rameez ul Hassan ${ }^{\mathrm{a}}$, Asdaq Farid ${ }^{\mathrm{b}}$ and Naveed Ahmad
}

${ }^{a}$ Department of Management Sciences, University of Haripur, Pakistan

${ }^{b}$ College of Business Administration, Chonnam National University, South Korea

${ }^{c}$ COMSATS Institute of Information Technology, Abbottabad, Pakistan

\section{H R O N I C L E}

Article history:

Received: October 1, 2016

Received in revised format: No-

vember 16, 2016

Accepted: January 7, 2017

Available online:

January 7, 2017

Keywords:

Cultural values

Emotional values

Word of mouth

Buying decision satisfaction

Gender

Millennial

\section{A B S T R A C T}

Consumer's values, Cultural values, Emotional Values and Word of mouth expressiveness, are good predictors for their buying decision satisfaction. In current study sample of 500 was taken to assess the consumer's buying decision satisfaction in relation to the importance of their values associated with those decisions. This study also reveals how gender influences buying decision satisfaction. Consumer values have a positive and significant impact on buying decision satisfaction. While evaluation on the basis of gender and females have more emotional and word of mouth linkages than males, on the contrary to this, males are more concerned with cultural values, and are less expressive and have a tendency to suppress their emotions while making buying decisions.

\section{Introduction}

On the basis of different regional and religious distributions, every society has unique cultural norms and traditions that transform consumer preferences and thus influence buying behavior accordingly. Collectivists are more concerned about others in their decisions, while their social desirability is higher than individualists (Hui, 1988). Therefore in a collectivist society, people are more concerned with each other and care more about their emotional values attached to their families and their society for maximum satisfaction in their decision makings. Emotions and social values have strong influences in collectivist societies, thus having a positive relation with purchasing behavior and a higher satisfaction level in comparison to individualistic cultures (Xiao \& Kim, 2009). Now, in collective cultures there are several pressures that are exerted by family, fellows, society, ideologies and other social norms on buying choices which are essence of decision satisfaction. With other consumption values, emotional

* Corresponding author.

E-mail address: raja.ahmed@uoh.edu.pk (R. A. Jamil) 
and social values are the causes of consumer preferences (Sheth et al., 1991). The immediate family is the first social circle, while making any purchase decision is made with priority given to their family members, as well as social acceptance, for maximum approval and intrinsic satisfaction regarding buying decisions. Along with economic utility, other pleasures and intangible values (Transactional Utility Theory) are strongly supported in collectivist societies. (McNeill et al., 2014). Therefore, emotional attachment apart from utilitarian benefits is also much more important in buying decisions in order to tie the families and their approvals in society. A higher level of care is given in collectivist societies and their ties to their families (Pyke \& Bengtson, 1996).

Purchase behavior is influenced by external factors such as cultural forces, economic forces and personal forces such as beliefs, attitudes, etc. (Grant \& Stephen, 2006). Cultural values significantly affect behavior (Lam et al., 2009). Consumer behavior is strongly connected with one's culture; this separation of culture from consumer behavior is impossible (Lukosius, 2004). The decision making process is an important concern in consumer behavior and it is affected by gender, in addition to the gender composition within the nuclear family when making any buying decisions (Lee \& Collins, 2000). Male dominancy was found in positive relation with cultural belongingness, while interaction also exists according to one's marital role in the process of decision making regarding purchase (Webster, 1994). Gender roles and cultural values observed in several studies have shown a strong influence on buying decisions (Bashir et al., 2013; Solka et al., 2011; Sun \& Merritt, 2004; Mahmood, 2002; Lee \& Robbins, 2000). A review of eighty six studies supports gender concern showing that males are effective in performing masculine roles and females in performing feminine roles (Eagly et al., 1995). In collectivist societies likes Pakistan where male dominancy rules, but a slight shift has been observed, and feminine involvement in the buying decision process has increased over the last few years. It has been remarked that females of this millennial group are accompanying their families in shopping or through individual shopping practices in urban areas. Due to the education younger females, interactions have increased in daily life matters and their role is changing in society in the area of family purchase decisions (Srivastava \& Anderson, 2010). At this time, gender roles are changing from the previous generation due to income, improved education, and other family dynamics (Kraft \& Weber, 2012). Women's actions are emotion oriented in purchase decisions, and we are interested to know why other women go for similar choices, as they made while males are interested to know the level of pleasure that others derives from similar purchases (Baker, 2012). As indicated in previous studies, gender has had a great influence on buying decisions with different feelings and satisfaction levels relating to their emotional and cultural values. In this study, we try to evaluate the role of gender in a male dominant culture like Pakistan, and how masculinity and femininity affect buying decision satisfaction, while the major role of emotional and cultural values of this millennial group are targeted. In collectivist cultures, strong interactions exists between people, and before decision making, people opt for suggestions, try to gain various benefits from the experiences of others, and listen to other's views in order to make the correct buying decisions. Word of mouth is another source for purchase decision satisfaction. Differences in referrals are noticed in a previous study on the base of national cultures like Japanese (collectivist) provide more referrals than Americans (Money et al., 1998). Thus due to strong connections and sharing in collectivist societies, word of mouth has a great impact on buying decision satisfaction. A referral group's influence is supported by the consumption decisions and thus results in changing preferences (Schiffman \& Kanuk, 1997). This study will highlight whether millennial group people are more expressive and advocate more about their positive experiences with products and services.

\section{Literature Review}

\subsection{Role of cultural values on buying decision}

Culture is the impact of collectivity on human personality which shapes human personality (Hofstede, 1980). Normative powers have potential to control the behaviors (Moschis \& Cox, 1989). Cultural Values play a vital role on influencing the human behaviors (Tybout \& Artz, 1994). While studying Japanese and American cultures with regards to purchase decision making, it was found that decision 
making is strongly backed by their cultures (Knight \& Calantone, 2000). In an impulse buying study of multi cultures it is supported that collectivism, individualism and other related factors have a great influence on buying behavior (Kacen \& Lee, 2002). Another study supports the dominancy of social norms that has a significant positive impact on individual's personal norms (Ahn et al., 2012). Social values are in strong connection in collectivist societies having a positive relation with purchasing behavior and a higher satisfaction level in comparison with individualism (Xiao \& Kim, 2009). Consumer decision making is different in varied cultures on behalf of their genders and cultural differences, so these aspects should be studied separately by marketers to satisfy their needs (Solka et al., 2011). Males are connected to social comparison while females are more connected to nurturance, care giving in relationships and physical closeness (Lee \& Robbins, 2000). On the basis of a lifestyle survey of individualistic and collectivist cultures, these cultures opposed each other on the basis of family orientation and role of gender (Sun \& Merritt, 2004). Cultural shifts have also been observed in a study which reveals that women of urban areas in Pakistan have almost equal participation in house hold matters, whereas women belonging to rural regions have their decision making dependent upon their husbands and other family members (Mahmood, 2002).Gender refers not only to biological characteristics but also qualities shaped by unique culture in men and women (DeMatteo, 1994). Gender role is an important variable of cultural values and the study noticed significant differences between male and female impulse buying behavior in Pakistan (Bashir et al., 2013).

\subsection{Role of word of mouth in buying decision}

Decisions regarding purchasing and information spread about commodities are guided by word of mouth (Soderlund \& Rosengren, 2007). When selecting a brand, WOM plays a vital role. Negative WOM is more influential than positive word of mouth thus affecting purchase chances (East et al., 2008; Podnar \& Javernik, 2012). Customer to customer communication and their communication quality has a significant impact on customer loyalty and satisfaction (Fakharyan et al., 2014). In online groups, buying intention and social factors are influenced by the media and personal referrals (Chen \& $\mathrm{Lu}, 2015)$. Complaint handling is the source to create positive WOM that will leads to more chances of retaining the customers (Yuksel et al., 2006). In an online assessment of consumer reliance on others' reviews; personal standing, knowledge and message comprehensiveness of reviewers are the influential sources to rely upon (Jamil \& Hasnu, 2013). WOM is more positive for self-relevant products than utilitarian products (Chung \& Darke, 2006). Customer advocacy has a strong connection with commitment and purchase intention (Mosavi \& Ghaedi, 2011). Family Members, fellows, and other close circles are the most reliable sources of word of mouth and have great control on the consumer's choices (Aslam et al., 2012). In an assessment of gender motivation, women have had a positive and significant relation with word of mouth and group affiliation (Swanson et al., 2003). Females are more expressive than males (Olsson \& Walker, 2003). Word of mouth is an influential source of marketing where male and female gender has played a differential role to deliver one's perceptions and service experiences to others (Sun \& Qu, 2011).

\subsection{Role of emotional values in buying decision}

In order to govern humans, the key variable is emotional influence (Andrade, 2014).In an automobile buying study of Asians and Europeans, it is revealed that exterior-interior designing, fragrances, color schemes, and seats coverings have a greater impact on emotions and these emotions have significant effects while purchasing cars (Wellings et al., 2010; Khalid \& Helander, 2006). Consumer experiences have a strong influence on emotional values and customer satisfaction (Brunner-Sperdin \& Peters, 2009). Another study related to tourism reveals that consumption emotions are associated with how fairly services are provided and affect customer satisfaction ( $\mathrm{Su} \& \mathrm{Hsu}, 2013)$. Customer emotions are a better source for predicting their future behavior intention in contrast to customer satisfaction (Koenig-Lewis \& Palmer, 2008). The correct judgment of customers' perceived emotions by the sales force will strengthen the buyer-seller relationship and enhance selling performances (Kidwell et al., 2007). In impulse buying, the emotional satisfaction of consumers has a significant positive relation 
with buying behavior and purchase in developing nations (Dhurup, 2014). A higher level of emotional intelligence controls the personal desires of middle class women and in link their emotions with other family stakeholder's benefits which are sought by impulse buying (Nair \& Das, 2015). Women are reacting more emotionally to the outcomes of their preferences than men (Croson \& Gneezy, 2009). Emotions plays key role in buying decisions for women and story linkages for creating emotional appealing is a successful strategy for their purchase decisions (Baker, 2012). In a study related to gender stereotypes, women have a higher level of sensitivity; they are much more expressive and exhibit greater emotions (Olsson \& Walker, 2003).

\subsection{Buying decision satisfaction}

Decision and consumption pleasure is based on choice objectives and satisfaction, which are determined by individual preference, social norms, justification of purchases, built confidence of purchase and minimize the regret, cost related factors and any negative associated factor which will leads to more product recommendation and association with product (Heitmann et al., 2007).Interior decor and a customer oriented atmosphere provides good experience and positive emotions in service related products that will positively influence customer satisfaction (Brunner-Sperdin \& Peters, 2009). Study of clothes designing disclose with economic factors socio-cultural forces also determines the individual's buying behavior thus marketers should highlights these aspects for more satisfaction designing clothes for varied markets (Lawan \& Zanna, 2013). Consumer decision making is different in varied cultures on behalf of their genders and cultural differences, so these aspects should be studied separately by marketers to satisfy their needs (Solka et al., 2011). Gender role is changing in societies; younger and educated female contributions in daily life are increasing, so the marketer should examine such roles. Along with males, it is suitable to target females as well, for family purchase decisions (Srivastava \& Anderson, 2010). Narratives are more influential in affecting the emotions of women, and these emotions leads to purchase decisions (Baker, 2012).

\section{Research Methodology}

\subsection{Hypotheses}

H1: Cultural values have significant effects on buying decision satisfaction.

H2: Emotional values have significant effects on buying decision satisfaction.

H3: Word of mouth has significant effects on buying decision satisfaction.

H4: Millennial Males and Females are associated with their cultural values and have significant effects on buying decision satisfaction.

H5: Millennial Females are more expressive than males and for both males/females have significant effects on buying decision satisfaction.

H6: Millennial Females are more emotional and have significant effects on buying decision satisfaction.

\subsection{Conceptual framework}

Conceptual framework for this study is shown in the Fig. 1. There are three independent variables i.e. emotional values, cultural values, and eWOM communication. The criterion variable is buying decision satisfaction. This study also checks for the influence of gender in overall relationship between predictor and criterion variables.

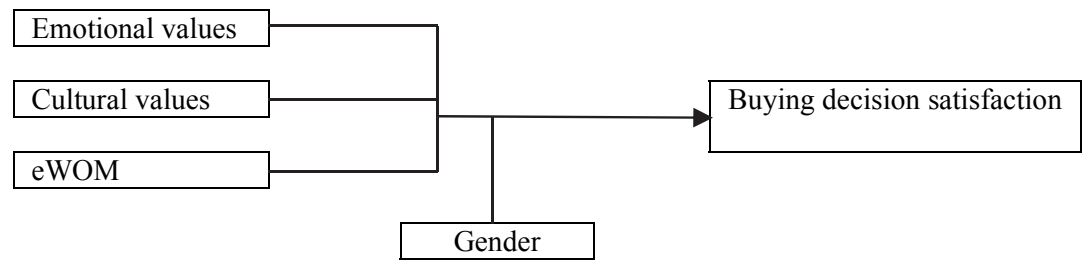

Fig. 1. Conceptual framework 


\subsection{Population and Sample}

A total of 500 people were selected from several universities located in Pakistan. Respondents were approached using both online surveys and the physical distribution of questionnaires. The targeted population was selected because they were from the millennial age group as well as being currently more engaged in buying practices in comparison to previous decades. In order to access the true customer values of millennial, university students are the best fit for true representation. With both types of questionnaires (online survey/physical) distributed we ensured the equal participation of gender to achieve true outcomes for the study by their true representation to ensure the role of gender and its impact. Our area of targeted population is the millennial age group ranging between 18- 40 years.

\subsection{Descriptive statistics}

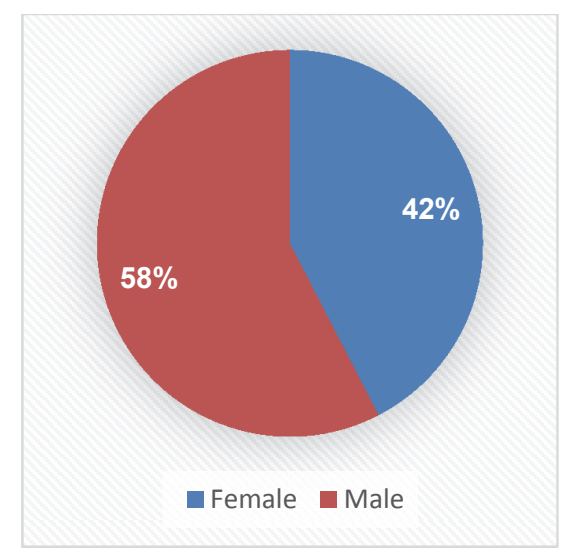

Gender

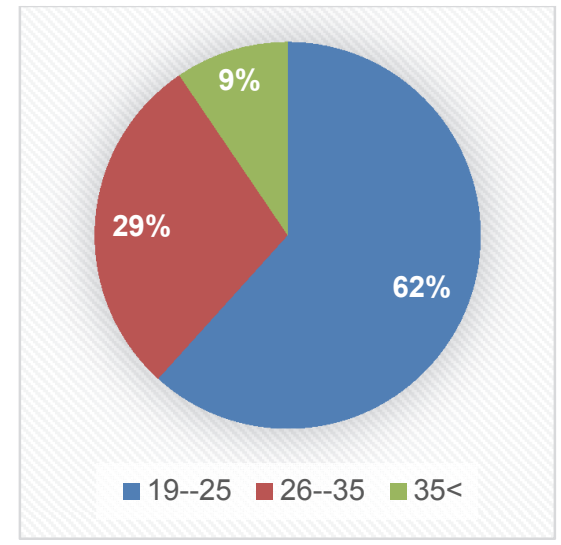

Education

Fig. 2. Descriptive statistics

A total number of 300 questionnaires were distributed physically from which were 280 were in useable condition. The remaining 200 hundred responses were collected through an online survey form with the help of different peers via Google docs. Thus, the sum of the total response was 480 with a response rate of $(96 \%)$. The major reason for the high response rate is the use of personal linkages for data collection and on the spot filling of questionnaires at several universities, as well as students taking a keen interest in activities related to research work. The survey yielded that the usable responses were $42.4 \%$ were female and $57.6 \%$ were male. Where The majority of respondents $(61.7 \%)$ were between the ages of 19 to 25 years, the second highest respondent group link aged 26-35 years with a percentage of $(28.8 \%)$, and the rest of the respondents aged 36 or above with their percentage contribution of $(9.5 \%)$.

\subsection{Design}

We made two segments of the said population, with half of the population having completed the online survey for their responses and half of population having filled out the physically distributed questionnaire for data collection. This technique enabled us to get online responses from educated people with higher education, and via the physically distributed questionnaire, we collected data from several households and students with lower education from the age of eighteen years or above. This was a generic study conducted without specifying any single product with the intention of attaining responses directed towards buying decision satisfaction. For data collection, we used convenience sampling.

\subsection{Data analysis}

SPSS version 21 was used to analyze the data. We performed linear regression to evaluate the impact of independent variables on dependent variables. To test the impact upon different genders, the data file was split and run for regression separately. 


\subsection{Scale or measured used}

Instruments used for the collection of data were adapted from several studies on the five point Likert scale. For emotional values, questions are adapted from studies analyzing the relationship between consumption values and brand loyalty among young people. Scale was adopted from a study on personal care products (Candan et al., 2013) which was originally developed by (Sheth et al., 1991) to measure consumption values. To measure cultural values, we adapted a set of seven questions from the electronic thesis of a study conducted at The Florida State University DigiNole on Common Cultural Differences and Their Effect on Consumer Behavior by (Alkhalaf, 2008). A set of questions related to the dependent variable buying decision satisfaction are taken from study of Brand choice behavior as a function of information load (Jacoby, Speller \& Kohn, 1974). In order to measure word of mouth, expressiveness items used are generated by Harrison-Walker (2001).

\subsection{Regression analysis}

As linear regression is performed during the analysis for all the independent variables for evaluating their impact on dependent variables we come to know several findings.

\subsection{Cultural Values}

Cultural values for millennial generation results have shown significant positive effect on their buying decision satisfaction $(\beta=.145, \mathrm{P}<.05)$ and support the $\mathrm{H} 1$ that buying decision is always influenced by the culture for satisfaction. This result is supported by earlier findings of (Knight \& Calantone, 2000; Xiao \& Kim, 2009; Solka et al., 2011; Ahn et al., 2012).

\subsection{Regression Analyses}

\section{Table 1}

Regression analysis (overall effect)

\begin{tabular}{lllll}
\hline Independent Variables & $\mathrm{B}$ & Std. Error & $\mathrm{T}$ & Sig. \\
\hline Cultural Values & .145 & .119 & 1.216 & .028 \\
Emotional Values & .291 & .155 & 1.874 & .066 \\
Word of Mouth & .371 & .170 & 2.184 & .033 \\
\hline
\end{tabular}

Dependent Variable: Buying Decision Satisfaction

\subsection{Emotional values}

Targeting to emotions is also a great source that influences the decision satisfaction and we found positive significant linkage $(\beta=.291, \mathrm{P}<.010)$ thus emotional values have a significant impact on buying decision satisfaction (Nair \& Das, 2015; Andrade, 2014; Dhurup, 2014; Wellings et al., 2010) which is also in line with our hypothesis number two.

\subsection{Word of Mouth}

People belonging to the millennial group express their emotions via word of mouth which has a positive and significant impact on buying decision satisfaction $(\beta=.371, \mathrm{P}<.05)$ results of the study are in direction to our H3 which is also supported by literature (Chung \& Darke, 2006; Soderlund \& Rosengren, 2007; Podnar \& Javernik, 2012; Jamil \& Hasnu 2013; Fakharyan et al., 2014)

\subsection{Gender Role Assessment (Regression Analysis)}

While assessing the influence of gender role for cultural values, results indicate males are more influenced by their culture values in buying decision than females $(\beta=.218, \mathrm{P}<.05)$ than females $(\beta=.001$, $\mathrm{P}<.10$ ), Connection of males to socio-cultural values is stronger than females (Lee \& Robbins, 2000). Overall, both genders have significant effect and are positively associated with their culture for decision satisfaction; therefore our hypothesis four is accepted. Gender role is an important variable of cultural 
values and the study noticed significant differences between male and female impulse buying behavior in Pakistan (Bashir, et.al 2013).

\subsection{Role of Gender}

Table 2

Regression analysis (Females)

\begin{tabular}{lllll}
\hline & B & Std. Error & T & Sig. \\
\hline Cultural Values & .001 & .239 & .006 & .095 \\
Emotional Values & .538 & .210 & 2.562 & .017 \\
Word of Mouth & .726 & .273 & 2.660 & .013 \\
\hline
\end{tabular}

Dependent Variable: Buying Decision Satisfaction

Table 3

Regression analysis (Males)

\begin{tabular}{lllll}
\hline & B & Std. Error & T & Sig. \\
\hline Cultural Values & .218 & .136 & 1.604 & .017 \\
Emotional Values & -.008 & .231 & -.035 & .072 \\
Word of Mouth & .149 & .234 & .636 & .029 \\
\hline
\end{tabular}

Dependent Variable: Buying Decision Satisfaction

Females are more interactive and more expressive than males (Olsson \& Walker, 2003), their buying decision satisfaction is more influenced by word of mouth in comparison to males $(\beta=.726, \mathrm{P}<.05)$ in comparison to males $(\beta=.149, \mathrm{P}<.05)$ The male and female gender have differential roles to deliver their perceptions and experiences to others (Sun \& Qu, 2011).On the whole, our findings suggest that for both genders, buying decision is influenced by word of mouth or social group referrals, these results are also supportive of our H5.

As for emotional values, are concern females are more influenced by their emotions than males and their emotional values have a significant positive impact on buying decision satisfaction $(\beta=.538, \mathrm{P}<$ $.05)$ and is in line with our H6. Thus, for women, emotional satisfaction is an important element to target for buying decision satisfaction (Croson \& Gneezy, 2009; Baker, 2012; Nair \& Das, 2015; Olsson $\&$ Walker, 2003). Women's emotional recognition power is far better than men's, enabling them to process negative emotions in a better way. Female emotions and sensitivity levels are hence proven higher than males, putting them at a higher risk averse of emotional threats pertaining to their children and family (Hampson, van Anders \& Mullin, 2006). With regards to emotional values for males, there is a negative impact of emotional values on buying decision satisfaction $(\beta=-.008, \mathrm{P}<.010)$. As previous studies indicate, the relation that males are more connected to social comparisons while females made emotional comparisons ((Lee \& Robbins, 2000). We also found social values for males are dominant over emotional values. Men are not only attached with the emotional value, but they also critically evaluate the several associations that they identify with. There are five truths about males. Men seek enlightenment, they seek experience, they seek success on their own terms, they happily define themselves as principle-driven and they identify themselves as family-centric (Moore, 2008). So their choices are not based on emotional decisions but on totality of benefit sought.

Consumer decision making is different in varied cultures on behalf of their genders and cultural differences, so these aspects should be studied separately by marketers to satisfy their needs (Solka et al., 2011). Males are connected to social comparison while females are connected more to nurturance, care giving, relationships and physical closeness (Lee \& Robbins, 2000). On the basis of a lifestyle survey of individualistic and collectivist cultures, these cultures opposed each other on the basis of family orientation and role of gender (Sun \& Merritt, 2004). A cultural shift is also observed in a study which reveals that women of urban areas in Pakistan have almost equal participation in house hold matters, whereas women belonging to rural regions have their decision making dependent upon their husbands and other family members (Mahmood, 2002). Gender refers not only biological characteristics but also 
qualities shaped by unique culture in men and women (DeMatteo, 1994). Gender role is an important variable of cultural values and the study noticed significant differences between male and female impulse buying behavior in Pakistan (Bashir et al., 2013).

\section{Discussion}

Cultural values, emotional values and word of mouth all independent variables that have a positive significant impact on dependent variable buying decision satisfaction. The consumer of any product or service is not only satisfied with the utilitarian benefits but also other associations (values) which are used as independent variables. In an aforementioned relationship, this study highlighted the importance of those values. Pre-purchase decision is properly assessed by the buyer from different angles like how much they got collective benefit they get from their purchase, their emotional satisfaction and what others think about their buying decision and are directly or indirectly effect by that decision.

In collectivist societies, the term "others" and "relationships with others" is a major cause that enforces any buyer to make a decision. An individual who is solely responsible for the whole family does not go for his/her personal choice. He must care for the emotions of others and the norms of society in order to minimize post purchase dissonance to get maximum satisfaction. Thus, all decisions taken by any individual must be backed by the social acceptability which might come from a close family circle or other normative pressures. Generation to generation several changes occurred in the values of society but in this study it is noticed that millennial strongly associated with their normative values and collectivism in making buying decisions. The results of this study in its entirety, and after splitting the data file on the basis of gender indicates that cultural values association, emotional effects and customer advocacy behavior all have their own importance in buying decision making. The intensity of these values may vary depending on the nature of a product like high involvement/low involvement or by the purpose of consumption. Both males and females stick to their cultural norms but the implementation of cultural values implementation is found higher in males. Males are dominant in asocial cultures like Pakistan and are usually the sole earning factor having decisional power. As a result, they have dominancy to direct the females towards their cultural association and care about cultural values while making buying decisions (Mahmood, 2002). Therefore their cultural orientation is higher than that of females.

Both genders suppressed their personal emotions over collective emotions to match socio-cultural values; their emotions are controlled by their close circle family members in order to satisfy their whole family by their buying decisions. Females are more concerned about their close family circle when making buying decisions, while males are more conscious about their dominancy and gender role to shape with cultural values rather than emotional values in buying decision. Another reason for the negative impact of emotions and buying decision satisfaction for males is their limited income. They have to think rationally rather than emotionally in purchase decision as they are considered the budget controller or main financer for the family. This assumption may not remain true in the case of unusual occurrences or in emergency situations.

Females are more highly expressive than males and narrate their positive association with buying decisions. Usually females have more time to interact with each other as they usually take part only in household matters. They not only provide information about their experience with the product or service but also the benefits, features and comparison of that product with other rivalry products. They tell more about the product they like and endorse it to others. In the case of branded or differentiated products they speak more in favor of their choice. On the other hand males are socially considered less talkative than females in Pakistan, and they usually provide information or suggestion at the time they are asked about or where it is necessary to tell or guide others in their buying decisions. WOM affects both genders but female's reliance on word of mouth is noticed higher than that of males. The reason behind this factor is they not only listen to other females but also seek suggestion from the family head like a husband, father etc. to gain maximum satisfaction from their buying decision. 


\section{Conclusion}

Pakistan is a collectivist culture country where people live together in a family system and all the close circles of the family are influenced by the decisions of a man of authority. Therefore, every decision is taken after proper analysis of the situation. Sociocultural pressures influence people to make buying decisions according to the norms of the society rather than their own choice. Buying decision is very much influenced by the emotional values of customers which enforce them to react in a certain way in order to get the highest level of satisfaction. These emotional values tend to cause the decision maker to suppress their own emotions over the emotional care of others, especially the close family. In the area of emotional targeting, females are the most appropriate section rather than males. Females are more sensitive and they are more communicative about their sentiments, thus emotional appealing is a successful tool for influencing females in their buying decisions in Pakistan. Where advocacy behavior is concerned, females advocate more about their good or bad experiences with products or services in comparison to males. When decision making is solely on the part of females, they are more conscious and go for the suggestions of others, relying on experienced and trustworthy people according to their own perception.

\subsection{Limitations}

- Emergency situations may have different effects on buying decisions related to necessities, products or services.

- Increased sample size may give us a better picture for proper generalization.

- This is a cross-sectional study conducted in a limited time frame, and therefore might bring with new outcomes if the study is longitudinal.

- This study told about the consumer behavior of Pakistan. Results in other collectivist countries may differ.

- The tradeoff between the choices due to the limited income of the people in the underdeveloped country of Pakistan is another reason to think about collective benefits. Results may be totally different in developed collectivist countries where people have a higher level of disposable income.

\subsection{Managerial implications}

- Organizations should focus more on personal suggestions and recommendations of one customer to another or on the customer to customer information spread by their quality offering through the satisfied customer.

- Females are the more appropriate gender as communication is typically passed via positive word of mouth, but at the same time any negative experience will lead to much worse results. Therefore any buying decision in which there is involvement of females should be handled in careful manners to meet the promises thus providing a high level of satisfaction.

- Communication management is the essence of modern marketing. Managers should target the right person for emotional appealing, provide true information and make good experiences for the customers.

- Organization should increase personal interaction with customers to build more confidence.

- Managers should invest more on family incentive promotional activities.

- Managers should hire gatekeepers in profitable markets for high involvement products for the provision of maximum information, properly implementing complaint management cells in approachable market areas; they should chalk policy for complaint handling to minimize the effect of negative word of mouth.

- Contents of advertisement should be delivered in accordance with societal acceptability; information search process should be easier and simpler. It becomes more influential if the literature provided by the organization in both national and international languages. 


\subsection{Future research}

Researchers can expand this study to make comparisons between developed and underdeveloped collectivist countries where huge disposable per capita income difference exists. This difference has ultimately effect on buying decisions both type of nations. Millennials can also be compared with Baby boomers in order to access the consumer values on the basis of generational differences within the same country. Longitudinal analysis with the same variables will generate more reliable results for drawing inferences.

\section{References}

Ahn, J. M., Koo, D. M., \& Chang, H. S. (2012). Different impacts of normative influences on proenvironmental purchasing behavior explained by differences in individual characteristics. Journal of Global Scholars of Marketing Science, 22(2), 163-182

Andrade, D. P. (2014). Governing 'emotional'life: passions, moral sentiments and emotions. International Review of Sociology, 24(1), 110-129.

Alkhalaf, A. A. (2008). Cultural Differences and Their Effect on Consumer Behavior. Electronic Theses, Treatises and Dissertations. Paper 168.

Aslam, S., Jadoon, E., Zaman, K., \& Gondal, S. (2012). Effect of word of mouth on consumer buying behavior. MJSS, 1, 2 .

Brunner-Sperdin, A., \& Peters, M. (2009). What influences guests' emotions? The case of high-quality hotels. International Journal of Tourism Research, 11(2), 171-183.

Baker, A. (2012).Gender Differences In Decision Making. Retrieved September 9, 2012, from http://www.decision-makingconfidence.com/gender-differences-in-decision-making.html

Bashir, S., Zeeshan, M. U. H. A. M. M. A. D., Sabbar, S. A. B. B. A. R. D. A. H. H. A. M., Hussain, R. I., \& Sarki, I. H. (2013). Impact of cultural values and life style on impulse buying behavior: a case study of Pakistan. International Review of Management and Business Research, 2(1), 193-200.

Candan, B., Ünal, S., \& Erciş, A. (2013). Analysing the relationship between consumption values and brand loyalty of young people: A study on personal care products. Management, 29, 46.

Croson, R. \& Gneezy, U. (2009). Gender differences in preferences. Journal of Economic Literature $47,448-474$.

Chen, Y. F., \& Lu, H. F. (2015). We-commerce: Exploring factors influencing online group-buying intention in Taiwan from a conformity perspective. Asian Journal of Social Psychology, 18(1), 6275.

Chung, C. M., \& Darke, P. R. (2006). The consumer as advocate: Self-relevance, culture, and word-ofmouth. Marketing Letters, 17(4), 269-279.

Dhurup, M. (2014). Impulsive Fashion Apparel Consumption: The Role of Hedonism, Fashion Involvement and Emotional Gratification in Fashion Apparel Impulsive Buying Behaviour in a Developing Country. Mediterranean Journal of Social Sciences, 5(8), 168.

DeMatteo, L. A. (1994). From hierarchy to unity between men and women managers: towards an androgynous style of management. Women in Management Review, 9(7), 21-28.

East, R., Hammond, K., \& Lomax, W. (2008). Measuring the impact of positive and negative word of mouth on brand purchase probability. International Journal of Research in Marketing, 25(3), 215224.

Eagly, A., Karau, S., \& Makhijani, M. (1995). Gender and the effectiveness of leaders: A meta analysis. Journal of Personality and Social Psychology, 117, 125-145.

Fakharyan, M., Omidvar, S., Khodadadian, M. R., Jalilvand, M. R., \& Nasrolahi Vosta, L. (2014). Examining the Effect of Customer-to-Customer Interactions on Satisfaction, Loyalty, and Word-ofMouth Behaviors in the Hospitality Industry: The Mediating Role of Personal Interaction Quality and Service Atmospherics. Journal of Travel \& Tourism Marketing, 31(5), 610-626.

Grant, I. J., \& Stephen, G. R. (2006). Communicating culture: an examination of the buying behaviour of 'tweenage'girls and the key societal communicating factors influencing the buying process of fashion clothing. Journal of targeting, measurement and analysis for marketing, 14(2), 101-114. 
Hampson, E., van Anders, S. M., \& Mullin, L. I. (2006). A female advantage in the recognition of emotional facial expressions: Test of an evolutionary hypothesis. Evolution and Human Behavior, 27(6), 401-416.

Harrison-Walker, L. J. (2001). The measurement of word-of-mouth communication and an investigation of service quality and customer commitment as potential antecedents. Journal of service research, 4(1), 60-75.

Hui, C. H. (1988). Measurement of individualism-collectivism. Journal of research in personality, 22(1), 17-36.

Heitmann, M., Lehmann, D. R., \& Herrmann, A. (2007). Choice goal attainment and decision and consumption satisfaction. Journal of marketing research, 44(2), 234-250.

Jacoby, J., Speller, D. E., \& Kohn, C. A. (1974). Brand choice behavior as a function of information load. Journal of Marketing Research, 63-69.

Jamil, R. A., \& Hasnu, S. A. F. (2013). Consumer's Reliance on Word of Mouse: Influence on Consumer's Decision in an Online Information Asymmetry Context. Journal of Business \& Economics, 5(2), 171-205.

Kraft, H., \& Weber, J. M. (2012). A look at gender differences and marketing implications. International Journal of Business and Social Science, 3(21), 247-253.

Kacen, J. J., \& Lee, J. A. (2002). The influence of culture on consumer impulsive buying behavior. Journal of consumer psychology, 12(2), 163-176.

Knight, G. A., \& Calantone, R. J. (2000). A flexible model of consumer country-of-origin perceptions: A cross-cultural investigation. International Marketing Review, 17(2), 127-145.

Khalid, H. M., \& Helander, M. G. (2006). Customer emotional needs in product design. Concurrent Engineering, 14(3), 197-206.

Kidwell, B., McFarland, R. G., \& Avila, R. A. (2007). Perceiving emotion in the buyer-seller interchange: The moderated impact on performance. Journal of Personal Selling \& Sales Management, 27(2), 119-132.

Koenig-Lewis, N., \& Palmer, A. (2008). Experiential values over time-a comparison of measures of satisfaction and emotion. Journal of Marketing Management, 24(1-2), 69-85.

Lee, C. K. C., \& Collins, B. A. (2000). Family decision making and coalition patterns. European Journal of Marketing, 34(9/10), 1181-1198.

Lukosius, V. (2004). Consumer Behavior and Culture: Review Of Medium Being Reviewed Title Of Work Reviewed In Italics. Journal of Consumer Marketing, 21(6), 435-437.

Lam, D., Lee, A., \& Mizerski, R. (2009). The effects of cultural values in word-of-mouth communication. Journal of international marketing, 17(3), 55-70.

Lee, R. M., \& Robbins, S. B. (2000). Understanding social connectedness in college women and men. Journal of Counseling \& Development, 78(4), 484-491.

Lawan, L. A., \& Zanna, R. (2013). Evaluation of socio-cultural factors influencing consumer buying behaviour of clothes in Borno State, Nigeria. Int. J. Basic Appl. Sci, 1(3), 519-529.

McNeill, L. S., Fam, K. S., \& Chung, K. (2014). Applying transaction utility theory to sales promotionthe impact of culture on consumer satisfaction. The International Review of Retail, Distribution and Consumer Research, 24(2), 166-185.

Moore, R. J. (2008). He Said, She Said: Marketing to the Sexes. Retrieved September 3, 2012, from Dynamic Graphics \&

Create Magazine: http://dynamicgraphics.com/dgm/Article/28851/index.html

Money, R. B., Gilly, M. C., \& Graham, J. L. (1998). Explorations of national culture and word-ofmouth referral behavior in the purchase of industrial services in the United States and Japan. The Journal of Marketing, 76-87.

Moschis, G. P., \& Cox, D. (1989). Deviant consumer behavior. Advances in Consumer Research, 16(1), 732-737.

Mahmood, N. (2002). Women's Role in Domestic Decision-making in Pakistan: Implications for Reproductive Behaviour. The Pakistan Development Review, 121-148. 
Mosavi, S. A., \& Ghaedi, M. (2011, July). A survey on the relationships between perceived value and customer advocacy behavior. In International Conference on Innovation, Management and Service IPEDR (Vol. 14)., July).

Nair, D., \& Das, S. (2015). Impact of Emotional Intelligence on Impulse Buying and Product Value Proposition. European Journal of Business and Management, 7(1), 165-172.

Olsson, S., \& Walker, R. (2003). Through a gendered lens? Male and female executives 'representations of one another. Leadership \& Organization Development Journal, 24(7), 387-96.

Olsson, S., \& Walker, R. (2003). Through a gendered lens? Male and female executives' representations of one another. Leadership \& Organization Development Journal, 24(7), 387-96.

Pyke, K. D., \& Bengtson, V. L. (1996). Caring more or less: Individualistic and collectivist systems of family eldercare. Journal of Marriage and the Family, 379-392.

Podnar, K., \& Javernik, P. (2012). The effect of word of mouth on consumers' attitudes toward products and their purchase probability. Journal of Promotion Management, 18(2), 145-168.

Swanson, S. R., Gwinner, K., Larson, B. V., \& Janda, S. (2003). Motivations of college student game attendance and word-of-mouth behavior: the impact of gender differences. Sport Marketing Quarterly, 12(3), 151-162.

Sheth, J. N., Newman, B. I., \& Gross, B. L. (1991). Why we buy what we buy: a theory of consumption values. Journal of business research, 22(2), 159-170.

Schiffman, L.G. \& Kanuk L.L. (1997). Consumer Behavior. Prentice-Hall, 6th. Edition.

Sheth, J. N., Newman, B. I. \& Gross, B. L. (1991a). Consumption Values and Marketing Choices. South-Western Pub.

Solka, A., Jackson, V. P., \& Lee, M. Y. (2011). The influence of gender and culture on Generation Y consumer decision making styles. The International Review of Retail, Distribution and Consumer Research, 21(4), 391-409

Sun, T., Horn, M., \& Merritt, D. (2004). Values and lifestyles of individualists and collectivists: a study on Chinese, Japanese, British and US consumers. Journal of Consumer Marketing, 21(5), 318-331.

Söderlund, M., \& Rosengren, S. (2007). Receiving word-of-mouth from the service customer: An emotion-based effectiveness assessment. Journal of retailing and consumer services, 14(2), 123-136.

Sun, L. B., \& Qu, H. (2011). Is there any gender effect on the relationship between service quality and word-of-mouth?. Journal of Travel \& Tourism Marketing, 28(2), 210-224.

Srivastava, R. K., \& Anderson, B. B. (2010). Gender roles and family decision making: a study of Indian automobile purchases. International Journal of Services, Economics and Management, 2(2), 109-120.

Su, L., \& Hsu, M. K. (2013). Service fairness, consumption emotions, satisfaction, and behavioral intentions: The experience of Chinese heritage tourists. Journal of Travel \& Tourism Marketing, 30(8), 786-805.

Tybout, A. M., \& Artz, N. (1994). Consumer psychology. Annual review of psychology, 45(1), 131169

Webster, C. (1994). Effects of Hispanic ethnic identification on marital roles in the purchase decision process. Journal of Consumer Research, 319-331.

Wellings, T., Williams, M., \& Tennant, C. (2010). Understanding customers' holistic perception of switches in automotive human-machine interfaces.Applied ergonomics, 41(1), 8-17.

Xiao, G., \& Kim, J. O. (2009). The investigation of Chinese consumer values, consumption values, life satisfaction, and consumption behaviors. Psychology \& marketing, 26(7), 610-624.

Yuksel, A., Kilinc, U., \& Yuksel, F. (2006). Cross-national analysis of hotel customers' attitudes toward complaining and their complaining behaviours.Tourism Management, 27(1), 11-24.

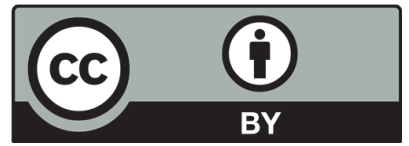

(C) 2017 by the authors; licensee Growing Science, Canada. This is an open access article distributed under the terms and conditions of the Creative Commons Attribution (CC-BY) license (http://creativecommons.org/licenses/by/4.0/). 